\title{
Numerical Simulation of Borehole Parameters for Coal Seam Gas Pre-Drainage
}

\author{
Xiaoyan $\mathrm{Li}^{1 *}$, Jiyu Zheng ${ }^{2}$, Jinpin Liu $^{3}$ \\ ${ }^{1}$ School of Energy \& Environment Engineering, Zhongyuan University of Technology, Zhengzhou 450007, China \\ ${ }^{2}$ School of Safety Engineering, Henan University of Engineering, Zhengzhou 451191, China \\ ${ }^{3}$ School of Resources and Safety Engineering, China University of Mining and Technology (Beijing), Beijing 100083, China
}

Corresponding Author Email: 6622@zut.edu.cn

https://doi.org/10.18280/ijht.390432

Received: 28 March 2021

Accepted: 2 June 2021

\section{Keywords:}

coal seam, gas, borehole parameters, numerical simulation

\begin{abstract}
Borehole parameters are quite important for gas drainage. This paper studies the impact of borehole diameter and time on gas drainage and performs numerical simulation on the distribution of gas pressure under the conditions of different borehole diameters and drainage times. The simulation results reveal that, as the borehole diameter increases, the gas drainage volume increases along with it and the gas pressure decreases, but such effect on gas drainage is limited. In terms of drainage time, the longer the drainage time, the greater the drainage impact scope. Taking a gas pressure drop of $51 \%$ as the indicator of the effective pre-drainage radius, the distance from the point with a gas pressure drop of $51 \%$ to the position of the borehole is the effective pre-drainage radius. When the predrainage reached the $30 \mathrm{th}, 45 \mathrm{th}, 60 \mathrm{th}, 75 \mathrm{th}$, and 90 th day, the effective pre-drainage radius was $1.04 \mathrm{~m}, 1.29 \mathrm{~m}, 1.51 \mathrm{~m}, 1.68 \mathrm{~m}$, and $1.82 \mathrm{~m}$ respectively. According to the numerical simulation results, the effective pre-drainage radius varies with the pre-drainage time, and the fitting analysis of the two indicates that the relationship between the two can be described by a power function.
\end{abstract}

\section{INTRODUCTION}

Gas disaster is the biggest hazard to the safe production of coal mines. Studies show that there're mainly two reasons for the small drainage volume and low drainage efficiency of coal mine gas, one is natural factors, since the coal seams in high gas and outburst mines are low-permeability coal seams, gas drainage (especially pre-drainage) is very difficult, moreover, there're differences in the coal seam gas content, working face gas emission source, and geological condition of each mine; the other reason is technical and managerial factors, such as the short drainage time, insufficient drilling quantity, poor borehole sealing quality, mismatched drainage system, and inadequate drainage management, etc. Based on these findings, targeted measures could be taken to optimize the working face gas drainage methods and parameters to increase gas drainage volume and gas drainage rate [1-3].

Key parameters of borehole drainage include drainage radius, drainage negative pressure, and borehole diameter. Existing studies on borehole parameters mostly focus on the drainage radius, few have concerned about the impact of drainage negative pressure and borehole diameter on gas drainage volume [4-6]. During coal seam gas pre-drainage, a pressure difference will be formed due to the existence of negative pressure around the borehole and the gas pressure of the coal seam, which would drive the gas to move towards the direction of the drainage borehole, forming an approximately circular-shaped drainage impact circle of radial flow; according to relevant formula, the drainage impact circle includes the drainage impact radius and the effective drainage radius [7-10].

Gas drainage should be based on the results of basic research. At present, three-dimensional models are mostly used to investigate the gas flow law under borehole deformation [11-13]. The pressure method is the principal method for measuring the drainage radius. Its principle is to determine the relationship between drainage radius and drainage time according to the change of gas pressure with pre-drainage time using regression analysis [14]. However, this method requires many boreholes, complicated procedures, high-quality borehole sealing, and long time, and its deviation is relatively large. Guo and Zhang [15] analyzed the shortcomings of the pressure drop method in measuring the drainage radius of boreholes, and proposed a new method of using SF6 tracer gas to measure the drainage radius, the proposed method is accurate, reliable, and easy to operate, and easy to observe on site. Zhang et al. [16] proposed to combine numerical simulation with actual measurement data to measure the drainage radius for coal seam gas pre-drainage, compared with the traditional pressure method, the proposed method needs less data and gives more accurate measurement results. To solve the poor practicability of existing coal seam gas drainage radius measurement methods, Liu et al. [17] derived a function describing the relationship between gas pressure change and gas drainage rate based on the parabolic equation of gas pressure and gas content, they developed a new technology that measures the drainage radius using relative pressure based on gas content, the technology uses the change of gas pressure with drainage time to determine the relationship between drainage radius and drainage time, thereby determining other parameters such as borehole spacing and drainage time, etc. Ma et al. [18] measured the drainage radius of boreholes on coal mining face in an outburst mine, then based on the measured data, they determined the 
scope of drainage radius, providing a reference of borehole parameters for coal seam gas drainage of outburst mines.

Computer numerical simulation is also an important method to study the parameters of gas drainage boreholes. Lin et al. [19] constructed a gas flow model for gas flowing in coal body around the boreholes, they wrote and complied a simulation program for calculating the gas flow surrounding the boreholes and used it to solve the relationship between effective drainage radius and drainage time, and they proposed a computer simulation method for determining the effective drainage radius of boreholes. Yuan and Shao [20] studied the method of hydraulic fracturing to improve the high permeability of coal and rock by using the method of numerical simulation. The research results show that the gas drainage effect can be improved by using hydraulic fracturing for coal and rock with certain hardness. Based on Darcy's law and Navier stocks, Yao et al. [21] calculated and analyzed the gas drainage in goaf of working face, and carried out CFD numerical simulation. It simulated the gas accumulation process in goaf and provided guidance for gas drainage. Du and Luo [22] analyzed the basic law of coal seam gas occurrence and flow, simulated the changes of basic parameters such as gas pressure field and velocity field around the borehole under the conditions of different gas drainage negative pressures at the working face, and performed a drainage test on site. Above-mentioned studies generally focused on a certain parameter, few has concerned about the overall impact of various parameters on gas drainage, therefore, future studies should pay attention to the impact of the drainage parameters of multiple boreholes on the gas drainage effect.

Pre-drainage of coal seam gas is a regional gas control measure, and the effect of pre-drainage is the guarantee for the safe production of coal mines. To achieve ideal gas drainage effect, it's necessary to determine reasonable gas drainage borehole parameters, and the optimal borehole parameters should be determined based on different borehole parameters and the drainage time. The optimization of borehole parameters is of great significance for improving the gas drainage rate. The content of this paper includes introduction, numerical model construction, numerical simulation result analysis, and conclusion.

\section{MODELING}

According to the actual situations of a mine site, the simulation in this study adopted a two-dimensional modeling method to construct a model with a size of length $\times$ width $=30 \mathrm{~m} \times 3 \mathrm{~m}$, as shown in Figure 1 below. The bottom of the model is a fixed boundary, the left and right sides are roller boundary, a load with a size of the weight of the overlying strata is applied from the top, and the middle part is the pre-drainage borehole; the measured coal seam gas pressure was $0.6 \mathrm{MPa}$, the drainage negative pressure was $20 \mathrm{kPa}$, the impact of borehole diameter on gas pre-drainage, and the impact of pre-drainage time on gas pressure distribution were simulated to determine the effective predrainage radius under different pre-drainage times, Figure 1 gives the geometric model, and Figure 2 gives the meshed triangular grids.

Physical property parameters required for the calculation are listed in Table 1, wherein $m$ is the Klikenberg coefficient; $\alpha$ is the Biot consolidation coefficient; $\rho_{s}$ is the density of the coal body; $\varphi_{0}$ is the initial porosity of the coal body; $k_{0}$ is the initial permeability of the coal body; $E$ is the elastic modulus; $v$ is the Poisson's ratio; $M$ is moisture content; $A$ is ash content; $\mu$ is the dynamic viscosity coefficient of $\mathrm{CH}_{4}$.

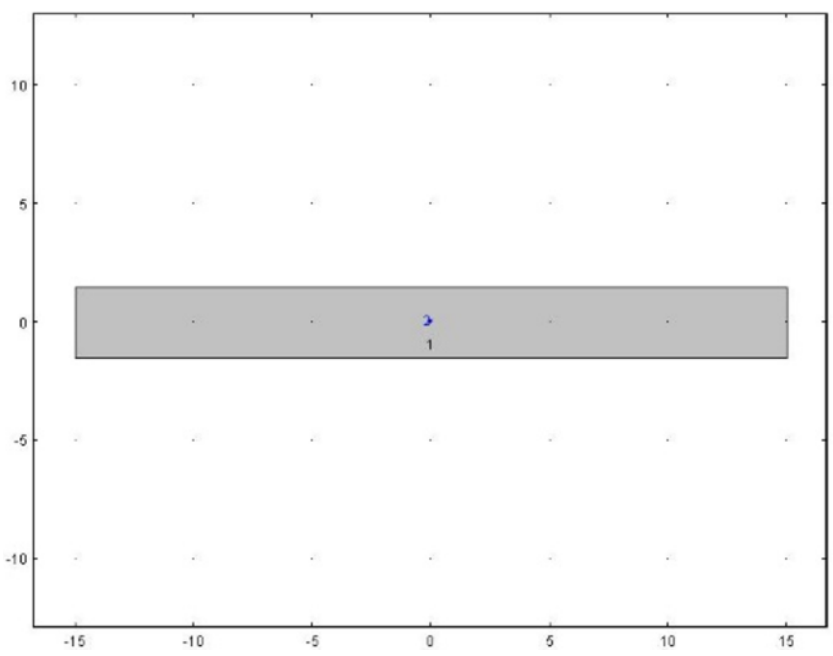

Figure 1. Geometric model

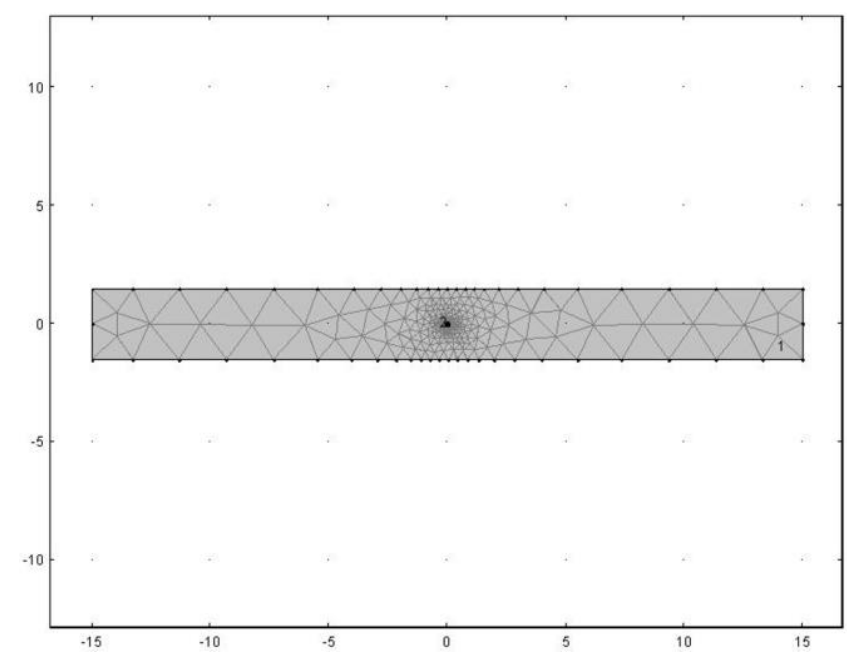

Figure 2. Grid distribution

Table 1. Parameters of numerical simulation

\begin{tabular}{cccccc}
\hline Parameter & $\mathrm{m}$ & $\alpha$ & $\rho_{s}\left(\mathrm{~kg} / \mathrm{m}^{3}\right)$ & $\varphi_{0}$ & $k_{0}\left(\mathrm{~m}^{2}\right)$ \\
\hline Value & $7.6 \times 10^{5}$ & 0.801 & $1.31 \times 10^{3}$ & 0.0828 & $2.7 \times 10^{-15}$ \\
Parameter & $\mathrm{E}(\mathrm{Mpa})$ & $v$ & $\mathrm{M}(\%)$ & $\mathrm{A}(\%)$ & $\mu\left(\mathrm{pa}^{*} \mathrm{~s}\right)$ \\
Value & 3500 & 0.3 & 1.7 & 11.59 & $1.08 \times 10^{-5}$ \\
\hline
\end{tabular}

\section{ANALYSIS OF NUMERICAL SIMULATION RESULTS}

\subsection{Gas pressure distribution under different borehole diameters}

Borehole diameter is a key parameter for gas drainage. If the borehole diameter is too small, it will affect the gas drainage effect, however, within a certain range, borehole diameter only has a small impact on gas drainage, thus it's not that the bigger the borehole diameter, the better. In the simulation, different borehole diameters were set to investigate the gas drainage effect, when borehole diameter 
$\mathrm{d}=75 \mathrm{~mm}$, the simulation results are shown in Figures 3-4:

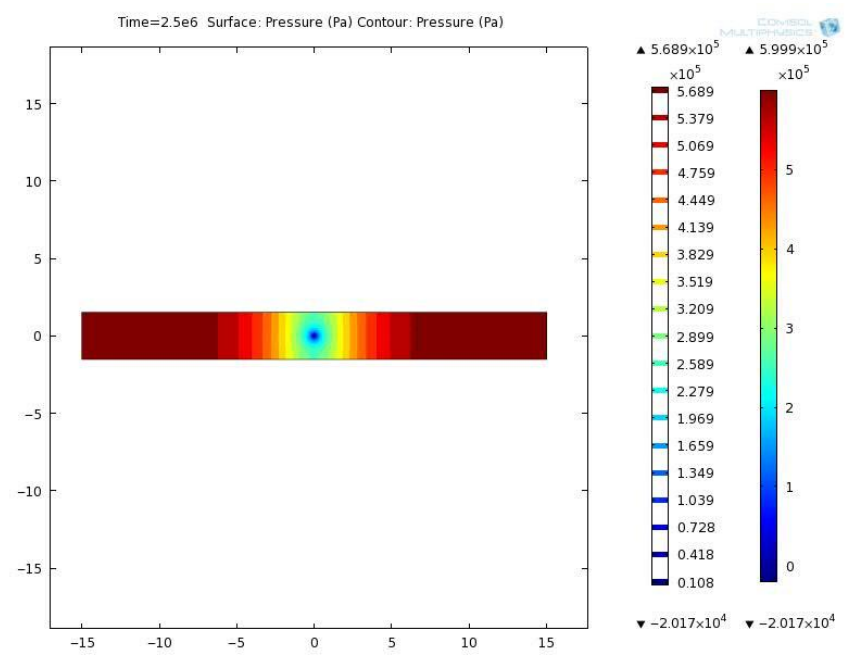

Figure 3. Gas pressure distribution contour when $d=75 \mathrm{~mm}$

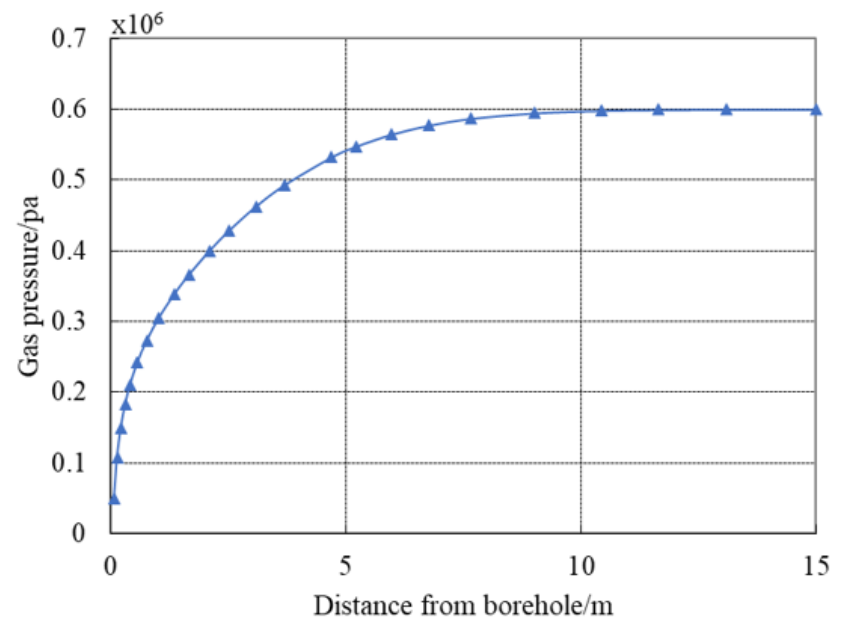

Figure 4. Gas pressure distribution curve when $d=75 \mathrm{~mm}$

When borehole diameter $\mathrm{d}=94 \mathrm{~mm}$, the simulation results are shown in Figures 5-6.

When borehole diameter $\mathrm{d}=108 \mathrm{~mm}$, the simulation results are shown in Figures 7-8.

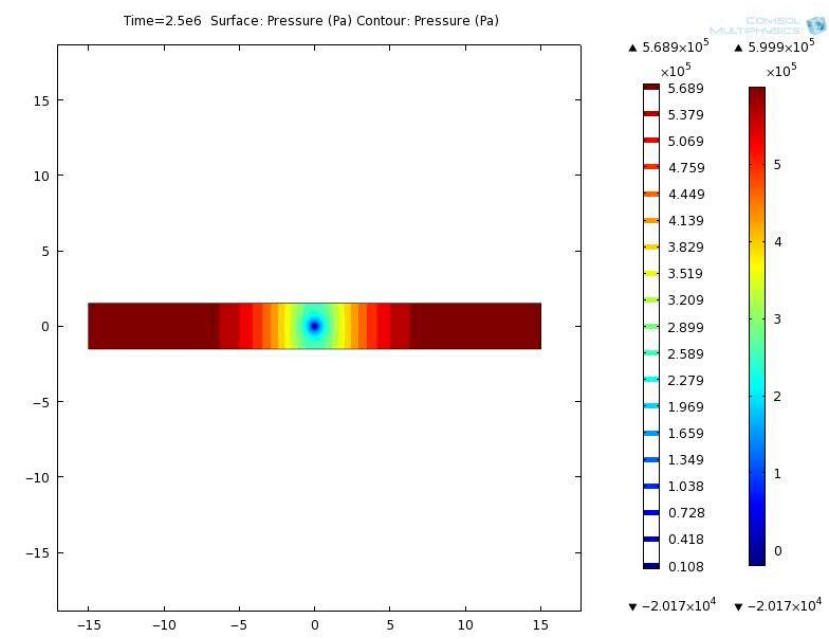

Figure 5. Gas pressure distribution contour when $d=94 \mathrm{~mm}$

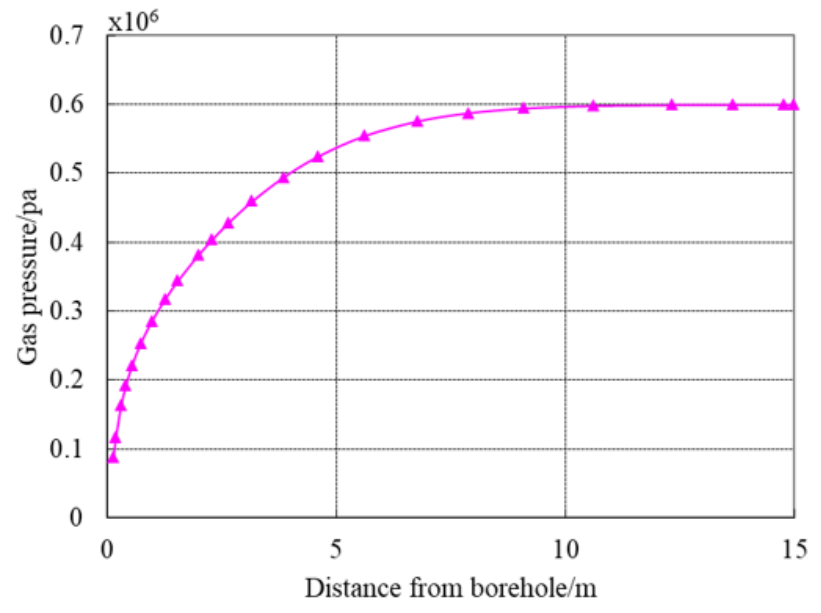

Figure 6. Gas pressure distribution curve when $d=94 \mathrm{~mm}$

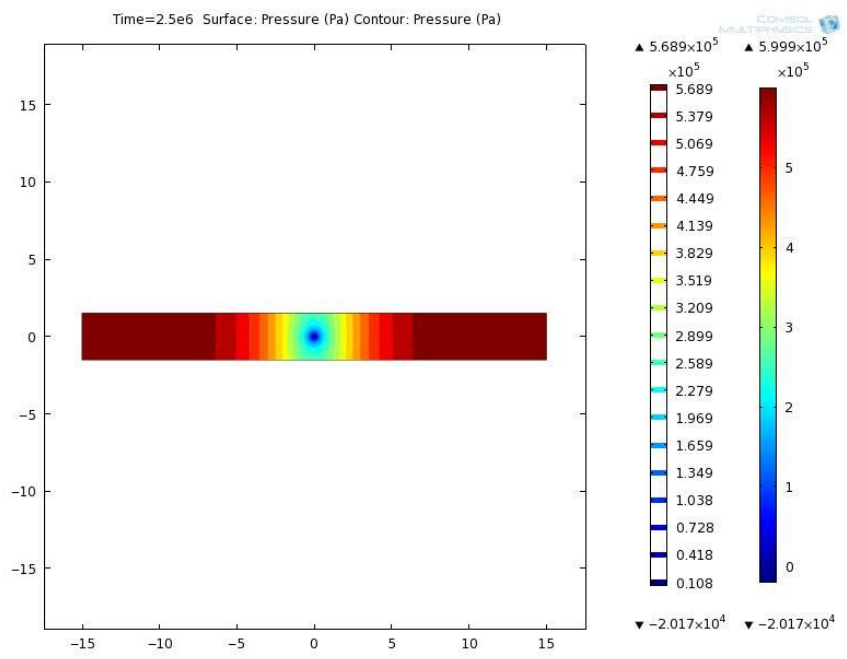

Figure 7. Gas pressure distribution contour when $d=108 \mathrm{~mm}$

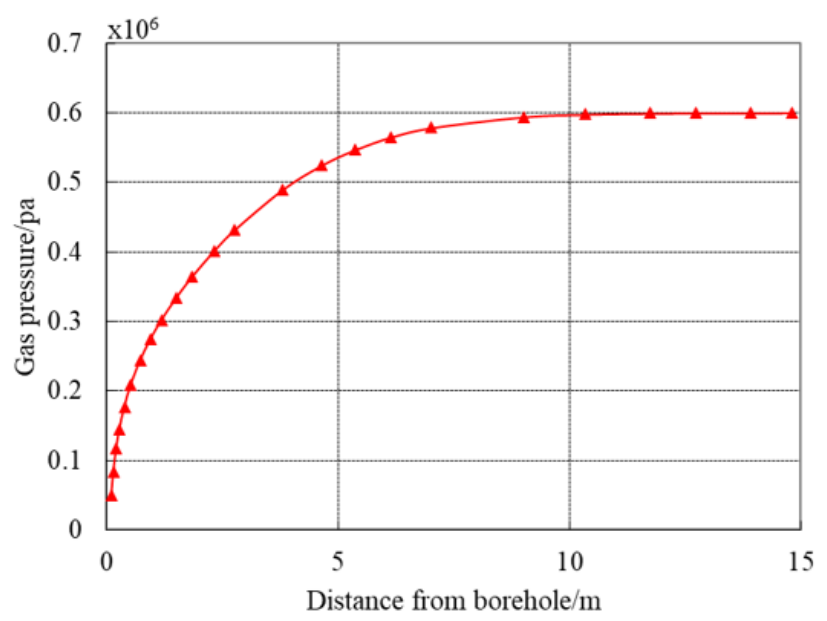

Figure 8. Gas pressure distribution curve when $d=108 \mathrm{~mm}$

The distribution of gas pressure under different borehole diameters is shown in Figure 9. As shown in Figure 9, as the borehole diameter increases, the gas drainage volume increases, the gas pressure decreases, but its impact on gas drainage is limited, for the three borehole diameters shown above, the difference in such impact was very small. The basic principle lies in that when the hole diameter becomes larger, the airtightness of the borehole is greatly challenged, so the borehole diameter increment and the borehole airtightness 
decrement would cancel each other. Therefore, in view of the actual conditions of the mining company, this study chose a borehole diameter of $94 \mathrm{~mm}$ to perform subsequent numerical simulation.

\subsection{Gas pressure distribution at different times}

Simulation results of gas pressure distribution under the above-mentioned three borehole diameters showed that, when borehole diameter was respectively $75 \mathrm{~mm}, 94 \mathrm{~mm}$, and $108 \mathrm{~mm}$, there's not much difference in the gas pressure distribution, indicating that the impact of borehole diameter on the effective drainage radius was limited. Based on the actual conditions of the surveyed coal mine, $94 \mathrm{~mm}$ was selected to be the borehole diameter to perform simulations on the relationship between pre-drainage time and gas pressure distribution and further obtain the relationship between predrainage time and effective drainage radius. The several figures below give the simulation results of gas pressure distribution at different pre-drainage times.
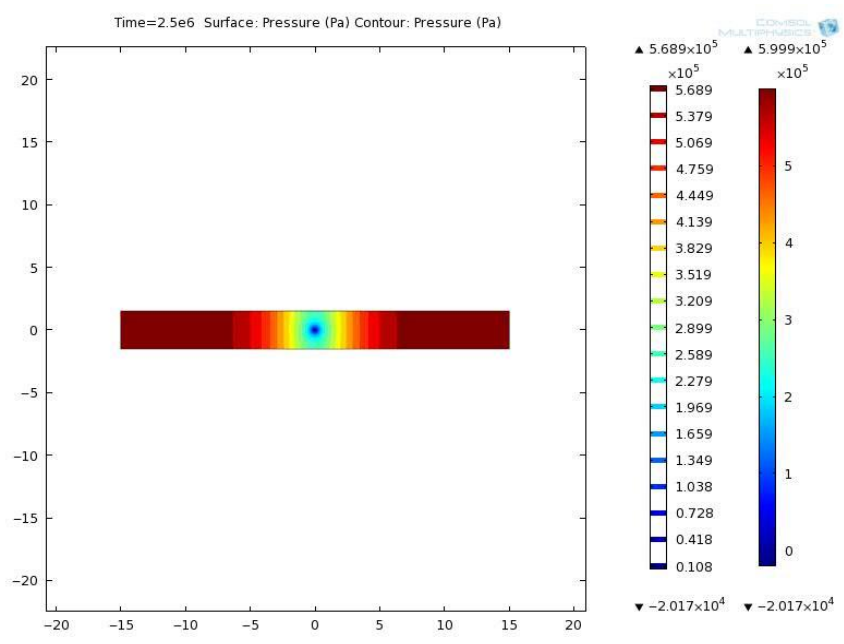

Figure 10. Gas pressure distribution contour when predrainage time $\mathrm{t}=30$ days
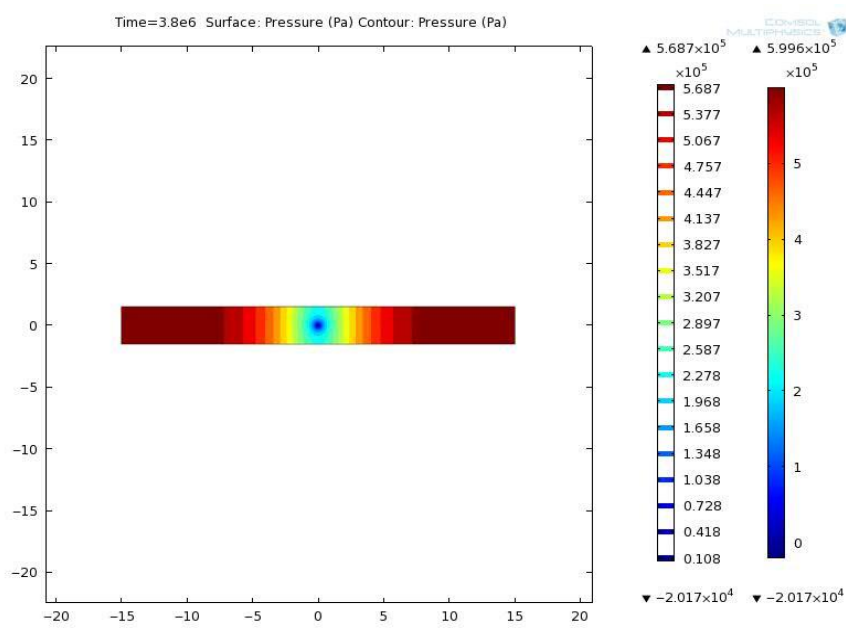

Figure 12. Gas pressure distribution contour when predrainage time $\mathrm{t}=45$ days
When the pre-drainage time $\mathrm{t}=30$ days, 45 days, 60 days, 75 days, and 90 days, the gas pressure distribution contours and curves are shown in Figures 10-19.

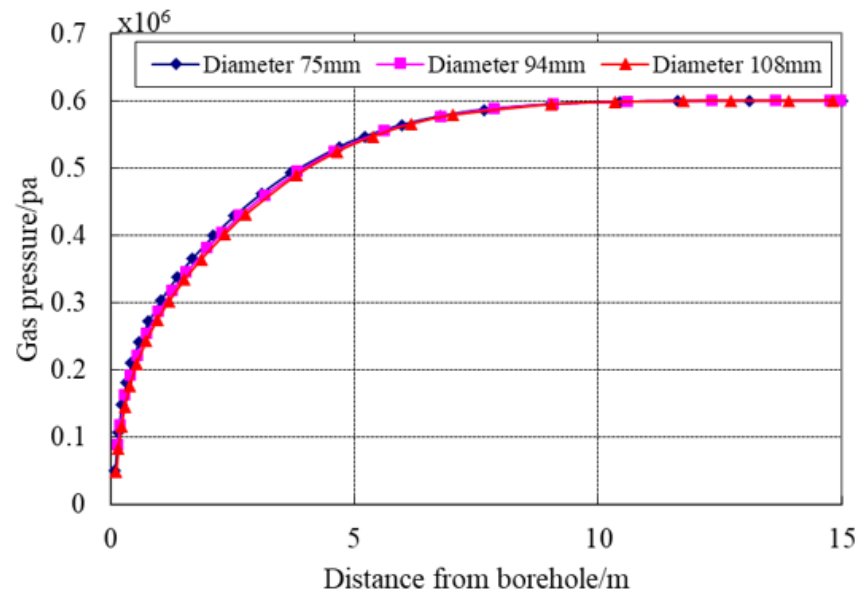

Figure 9. Distribution of gas pressure under different borehole diameters

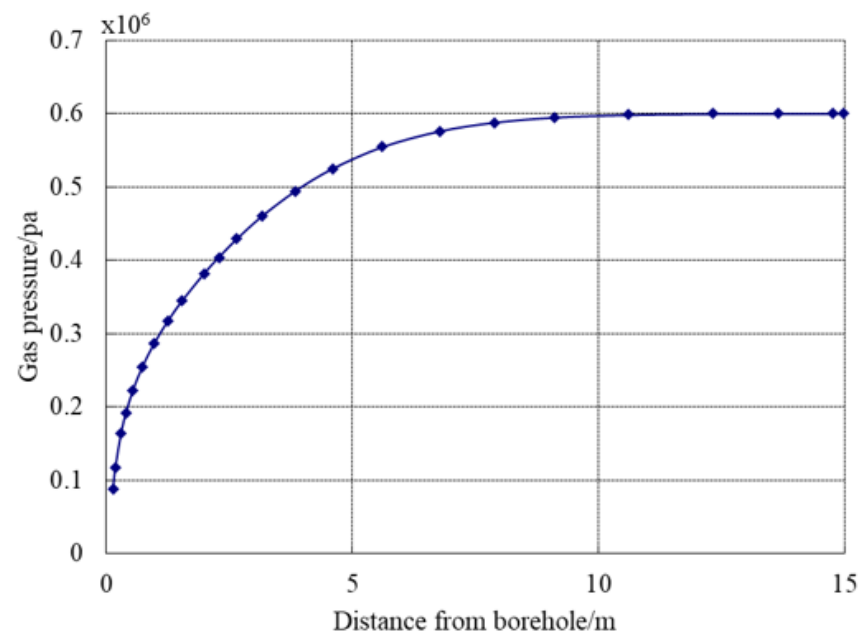

Figure 11. Gas pressure curve when pre-drainage time $t=30$ days

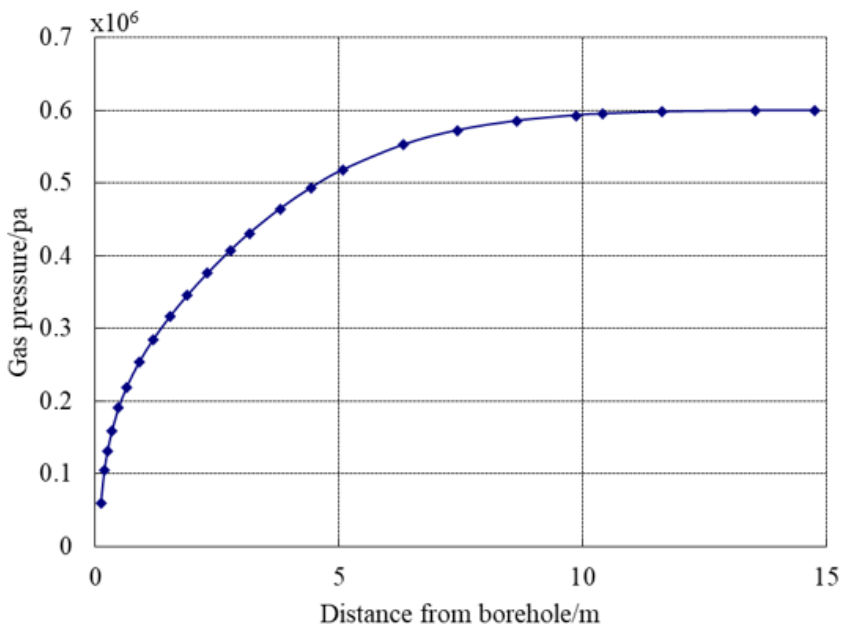

Figure 13. Gas pressure curve when pre-drainage time $t=45$ days 


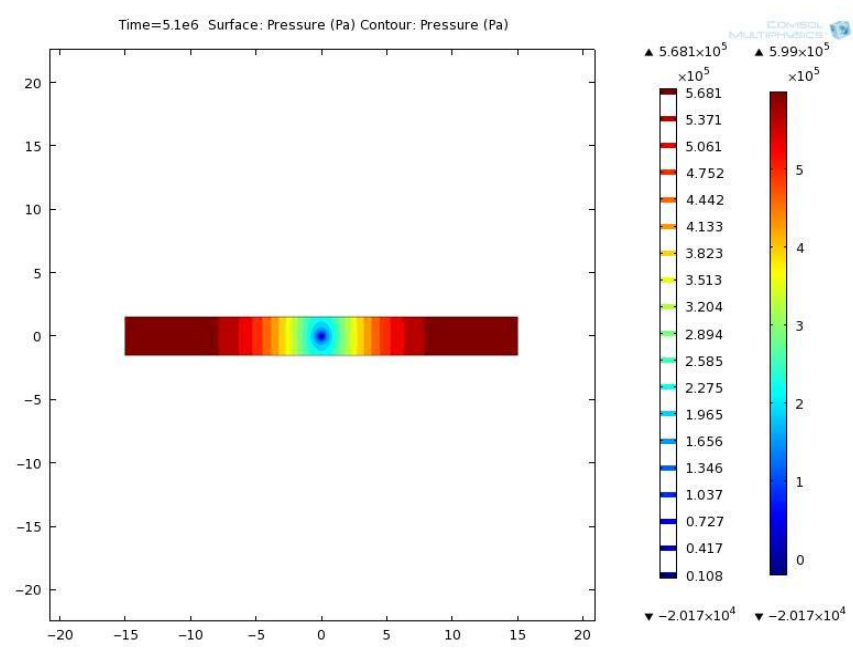

Figure 14. Gas pressure distribution contour when predrainage time $\mathrm{t}=60$ days

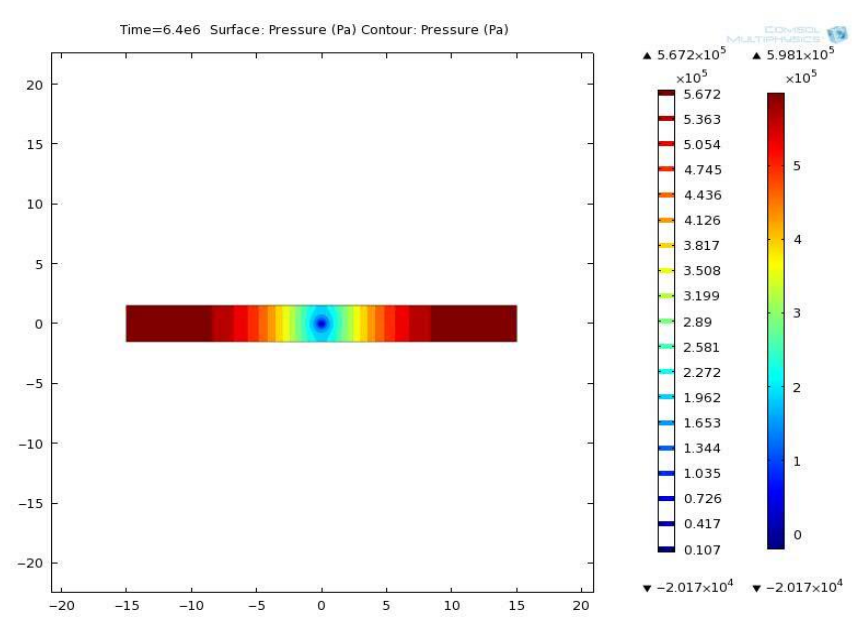

Figure 16. Gas pressure distribution contour when predrainage time $\mathrm{t}=75$ days
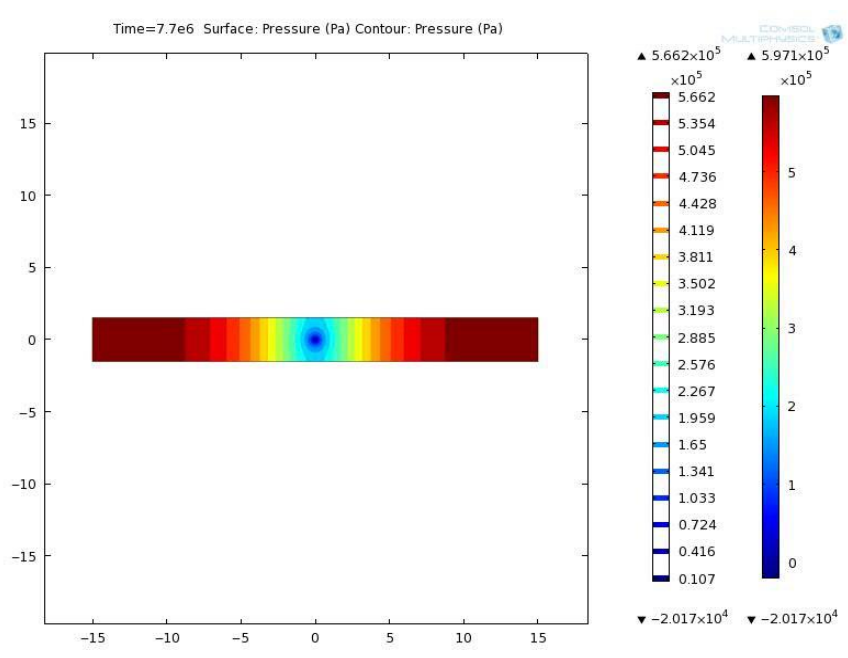

Figure 18. Gas pressure distribution contour when predrainage time $\mathrm{t}=90$ days

Figure 20 gives the relationship between gas pressure and the distance from pre-drainage borehole under different predrainage times.

According to these figures we can see that, with the increase of pre-drainage time, in case of a same distance from pre-

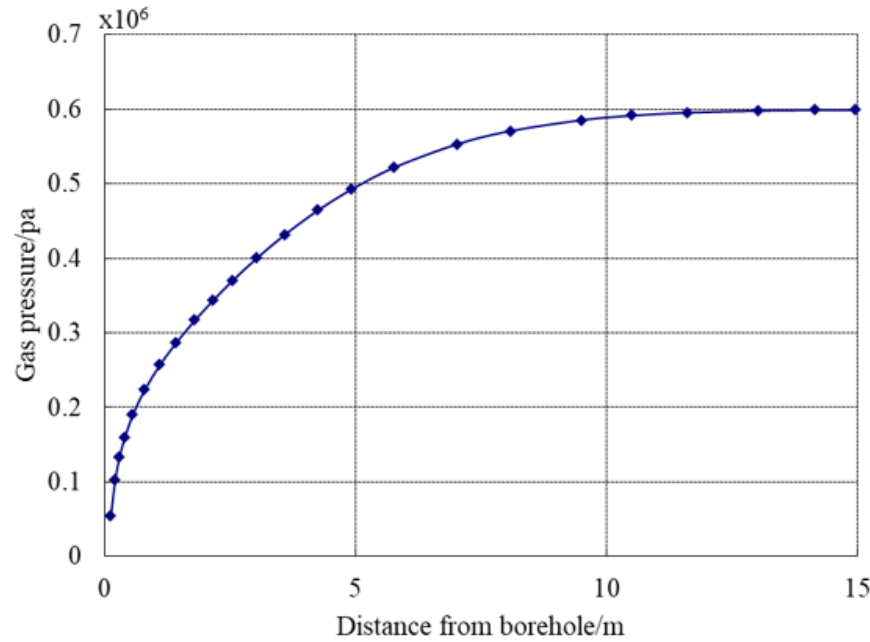

Figure 15. Gas pressure curve when pre-drainage time $t=60$ days

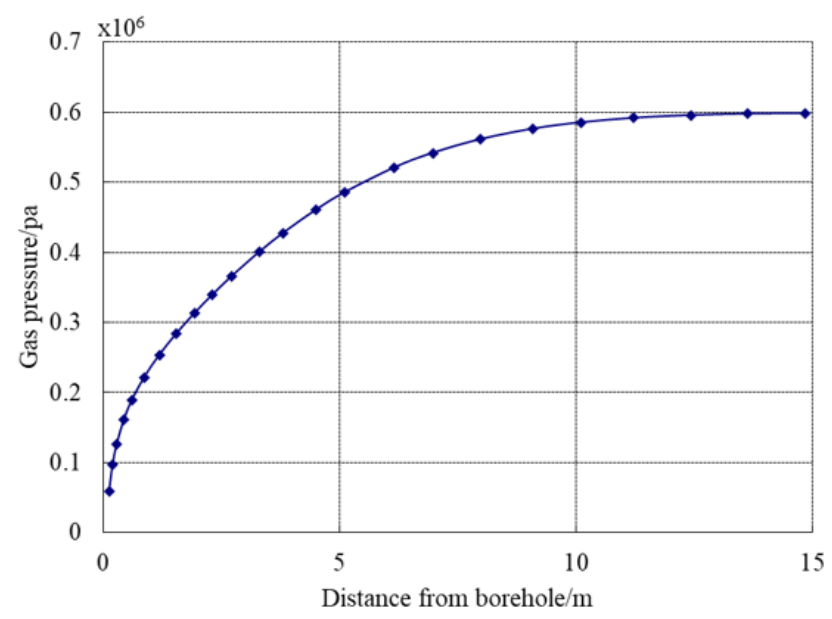

Figure 17. Gas pressure curve when pre-drainage time $t=75$ days

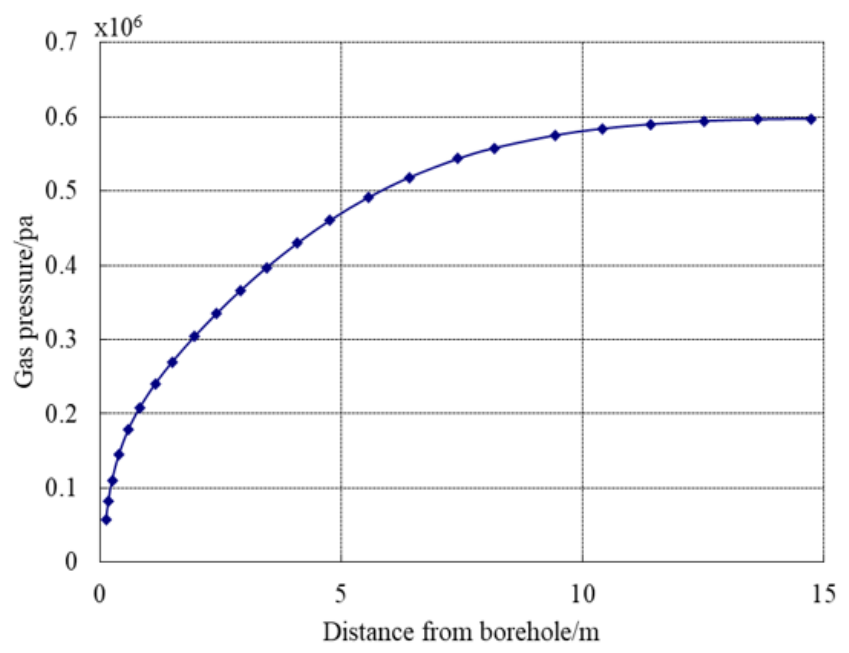

Figure 19. Gas pressure curve when pre-drainage time $t=90$ days

drainage borehole, the gas pressure decreases; with the increase of pre-drainage time, the impact scope of gas drainage enlarges, which is manifested as the increase in the distance between the drainage borehole and the point with the original gas pressure in the coal seam. Therefore, relative to the impact 
of borehole diameter on gas drainage, extending the drainage time can greatly improve the gas drainage effect and reduce the coal seam gas content. The principle is that gas drainage is affected by the permeability of the coal seam, and both natural desorption and negative pressure drainage would need a certain time.

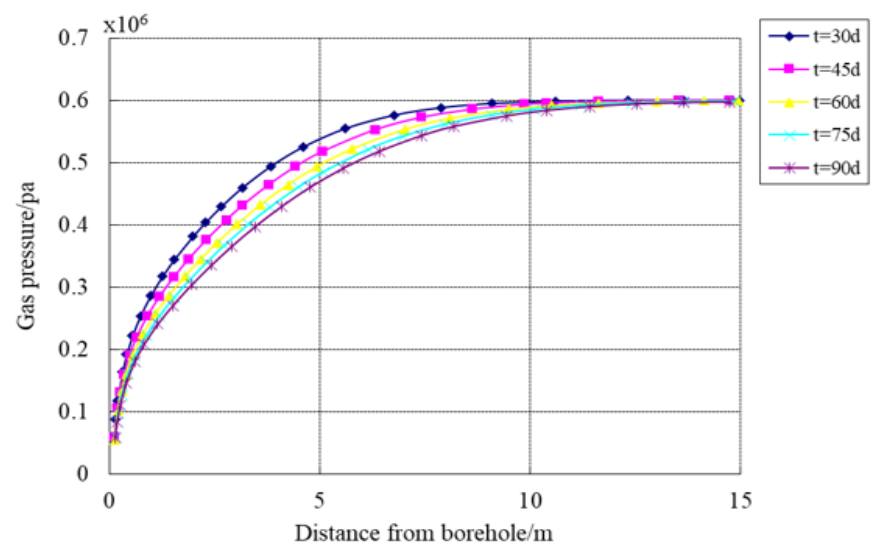

Figure 20. Changes of distance from borehole and gas pressure under different pre-drainage times

\subsection{The effective drainage radius of the borehole}

According to relevant regulations, after coal seam gas predrainage, the gas pre-drainage effect must be tested, and one of the test indicators is that the pre-drainage rate of coal seam gas should be greater than $30 \%$, that is, after drainage, the content of coal seam gas should be reduced by more than $30 \%$.

For the analysis and calculation of gas flow in engineering practice, under the conditions that the coal seam gas pressure is not very large, the parabolic equation of gas content can basically meet the requirements, the equation is: $X=\alpha \sqrt{ }$, where, $X$ is the coal seam gas content, $\mathrm{m}^{3} / \mathrm{t}$; $\alpha$ is gas content coefficient, $\mathrm{m}^{3} /\left(\mathrm{t} \cdot \mathrm{MPa}^{1 / 2}\right) ; p$ is the coal seam gas pressure, $\mathrm{MPa}$.

Therefore, there is a parabola-shaped relationship between coal seam gas content and gas pressure.

If the pre-drainage rate of coal seam gas is required to be $30 \%$, namely the residual gas content is $70 \%$ of the original gas content, then at this time, the residual gas pressure is $49 \%$ of the original gas pressure, and the gas pressure has dropped by $51 \%$. Therefore, the indicator of the effective drainage radius was determined as follows: after the gas pressure of the pressure-measuring borehole was stabilized, gas drainage operation was performed, and the gas pressure change of each pressure-measuring borehole was observed; boreholes with a gas pressure drop higher than $51 \%$ were regarded as ones within the effective drainage radius, and the distance from the farthest pressure-measuring borehole to the drainage borehole was regarded as the effective drainage radius. Therefore, the indicator of effective drainage radius was determined to be a gas pressure drop greater than $51 \%$.

According to above analysis, when the original gas pressure was $0.6 \mathrm{Mpa}$, the gas pressure dropped by $51 \%$, namely $0.306 \mathrm{Mpa}$, and the residual gas pressure was $0.294 \mathrm{Mpa}$. Therefore, we found that when the residual gas pressure was $0.294 \mathrm{Mpa}$, the distance from the pre-drainage borehole was the effective pre-drainage radius. When the pre-drainage time was 30 days, the effective pre-drainage radius was $1.04 \mathrm{~m}$; when the pre-drainage time was 45 days, the effective predrainage radius was $1.29 \mathrm{~m}$; when the pre-drainage time was 60 days, the effective pre-drainage radius was $1.51 \mathrm{~m}$; when the pre-drainage time was 75 days, the effective pre-drainage radius was $1.68 \mathrm{~m}$; when the pre-drainage time was 90 days, the effective pre-drainage radius was $1.82 \mathrm{~m}$.

Figure 21 gives the relationship between the effective predrainage radius and the pre-drainage time. The two exhibited a power function relationship, and the fitting formula is: $y=0.1823 x^{0.5137}$.

The regression coefficient $\mathrm{R}^{2}$ is 0.9986 , the correlation coefficient $\mathrm{R}=0.9993$, and the fitting curve is highly reliable.

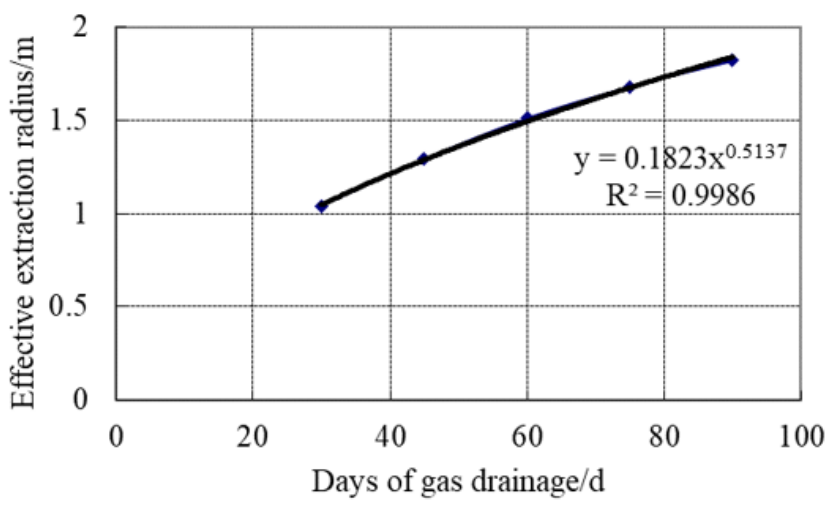

Figure 21. Relationship between effective pre-drainage radius and pre-drainage time

\section{CONCLUSIONS}

(1) This paper studied the impact of borehole diameter on gas drainage and investigated the gas pressure distribution in case of a borehole diameter of $75 \mathrm{~mm}, 94 \mathrm{~mm}$, and $108 \mathrm{~mm}$ through numerical simulation, the research results reveal that, as the borehole diameter increases, the gas drainage volume increases along with it and the gas pressure decreases, but such effect on gas drainage is limited.

(2) The changes in pre-drainage time and gas pressure were numerically simulated in case of a borehole diameter $\mathrm{d}=94 \mathrm{~mm}$; taking a gas pressure drop of $51 \%$ as the indicator of the effective pre-drainage radius, the distance from the point with a gas pressure drop of $51 \%$ to the position of the borehole is the effective pre-drainage radius, when the pre-drainage time reached the 30th day, the effective pre-drainage radius was $1.04 \mathrm{~m}$; when the pre-drainage time reached the 45 th day, the effective pre-drainage radius was $1.29 \mathrm{~m}$; when the predrainage time reached the 60th day, the effective pre-drainage radius was $1.51 \mathrm{~m}$; when the pre-drainage time reached the 75 th day, the effective pre-drainage radius was $1.68 \mathrm{~m}$; when the pre-drainage time reached the 90th day, the effective predrainage radius was $1.82 \mathrm{~m}$.

(3) According to the results of numerical simulation, the effective pre-drainage radius varied with the pre-drainage time. Fitting analysis on effective pre-drainage radius and predrainage time showed that the relationship between the two can be described by a power function, the regression coefficient was 0.9986 , indicating a high degree of fitting.

(4) The pressure drop method is a main method for determining effective pre-drainage radius, however, since this method is insensitive to pressure, inaccuracies might occur during the actual observation process, therefore it's necessary to consider the changes of multiple gas parameters and define a comprehensive parameter to determine the effective predrainage radius, and this is a matter that should be considered in the subsequent research. 


\section{ACKNOWLEDGEMENT}

This paper was supported by Industry-University Cooperative Talent Training Project, Chinese Ministry of Education (Grant No.: 202002135001).

\section{REFERENCES}

[1] Frank, H., Ting, R., Naj, A. (2013). Evolution and application of in-seam drilling for gas drainage. International Journal of Mining Science and Technology, 23(4): 543-553.

https://doi.org/10.1016/j.ijmst.2013.07.013

[2] Karacan, C.Ö., Ruiz, F.A., Cotè, M., Phipps, S. (2011). Coal mine methane: A review of capture and utilization practices with benefits to mining safety and to greenhouse gas reduction. International Journal of Coal Geology, 86(2-3): 121-156 https://doi.org/10.1016/j.coal.2011.02.009

[3] Lu, T., Yu, H., Zhou, T., Mao, J., Guo, B. (2009). Improvement of methane drainage in high gassy coal seam using waterjet technique. International Journal of Coal Geology, 79(1-2): 40-48. https://doi.org/10.1016/j.coal.2009.04.005

[4] Karacan, C.Ö., Diamond, W.P., Schatzel, S.J. (2007). Numerical analysis of the influence of in-seam horizontal methane drainage boreholes on longwall face emission rates. International Journal of Coal Geology, 72(1): 1532. https://doi.org/10.1016/j.coal.2006.12.007

[5] Zhou, F., Xia, T., Wang, X., Zhang, Y., Sun, Y., Liu, J. (2016). Recent developments in coal mine methane extraction and utilization in China: A review. Journal of Natural Gas Science and Engineering, 31: 437-458. https://doi.org/10.1016/j.jngse.2016.03.027

[6] Whittles, D.N., Lowndes, I.S., Kingman, S.W., Yates, C., Jobling, S. (2007). The stability of methane capture boreholes around a long wall coal panel. International Journal of Coal Geology, 71(2-3): 313-328. https://doi.org/10.1016/j.coal.2006.11.004

[7] Packham, R., Cinar, Y., Moreby, R. (2011). Simulation of an enhanced gas recovery field trial for coal mine gas management. International Journal of Coal Geology, 85(3-4):

247-256 https://doi.org/10.1016/j.coal.2010.11.013

[8] Iken, A., Fabri, K., Funk, M. (1996). Water storage and subglacial drainage conditions inferred from borehole measurements on Gornergletscher, Valais, Switzerland. Journal of Glaciology, 42(141): 233-248. https://doi.org/10.3189/S0022143000004093

[9] Medeiros, F., Ozkan, E., Kazemi, H. (2008). Productivity and area of fractured reservoirs in tight gas reservoirs. SPE Reservoir Evaluation \& Engineering, 11(5): 902911. https://doi.org/10.2523/108110-MS
[10] Xing, Y., Zhang, F. (2019). Optimizing borehole spacing for coal seam gas pre-drainage. Journal of Geophysics and $\quad$ Engineering, 16(2): 399-410. https://doi.org/10.1093/jge/gxz014

[11] Shen, B.H., Liu, J.Z., Zhang, H. (2007). The technical measures of gas control in China coal mines. Journal of China Coal Society, 32(7): 673-679. https://doi.org/10.1016/S1872-2067(07)60020-5

[12] Zhao, H., Li, J., Liu, Y., Wang, Y., Wang, T., Cheng, H. (2020). Experimental and measured research on threedimensional deformation law of gas drainage borehole in coal seam. International Journal of Mining Science and Technology, 30(3): 397-403. https://doi.org/10.1016/j.ijmst.2020.04.001

[13] Yue, G., Liu, H., Yue, J., Li, M., Liang, W. (2019). Influence radius of gas extraction borehole in an anisotropic coal seam: Underground in-situ measurement and modeling. Energy Science \& Engineering, 7(3): 694709. https://doi.org/10.1002/ese3.285

[14] Xu, D.F., Wang, Z.F. (2009). Experimental investigation on pressure falling method measuring the borehole's influence radius. Safety in Coal Mines, 40(5):1-3.

[15] Guo, L.J., Zhang, J. (2011). Determination of effective gas drainage radius of unrelieved coal seams. Coal Mine Safety, 9: 95-97.

[16] Zhang, C., Xu, J., Peng, S., Li, Q., Yan, F. (2019). Experimental study of drainage radius considering borehole interaction based on 3D monitoring of gas pressure in coal. Fuel, 239: 955-963. https://doi.org/10.1016/j.fuel.2018.11.092

[17] Liu, S.J., Ma, G., Lu, J., Lin, B.Q. (2011). Relative pressure determination technology for effective radius found on gas content. Journal of China Coal Society, 36(10): 1715-1719.

[18] Ma, G., Su, X.B., Wei, Q.X. (2009). The determination method of coal gas drainage radius based on methane flow state. Journal of China Coal Society, 34(4):501-504.

[19] Lin, H., Huang, M., Li, S., Zhang, C., Cheng, L. (2016). Numerical simulation of influence of Langmuir adsorption constant on gas drainage radius of drilling in coal seam. International Journal of Mining Science and Technology, 26(3): 377-382. https://doi.org/10.1016/j.ijmst.2016.02.002

[20] Yuan, Z., Shao, Y. (2018). Numerical modeling on hydraulic fracturing in coal-rock mass for enhancing gas drainage. Advances in Civil Engineering. https://doi.org/10.1155/2018/1485672

[21] Yao, W., Jin, L.Z., Zhang, J. (2010). Numerical simulation of gas drainage with high position boreholes in goaf. Journal of University of Science and Technology Beijing, 32(12): 1521-1525.

[22] Du, Z.S., Luo, H.Z. (2009). Measuring and calculation method of borehole effective gas drainage radius. Coal Science and Technology, 37(2): 59-62. 